\title{
Salivary proline rich peptide decreases cell growth in HCC38 triple negative breast cancer cell line
}

\author{
Charles F. Streckfus*, Daniel Arreola, Cynthia G. Streckfus, Lenora R. Bigler \\ Department of Diagnostic and Behavioral Sciences, University of Texas School of Dentistry, Houston, United States
}

Received: May 7, 2017

DOI: $10.5430 /$ jst.v7n2p38
Accepted: June 19, 2017

URL: https://doi.org/10.5430/jst.v7n2p38

\begin{abstract}
Objective: The objective of this study is to determine the effects of p1978 on the growth rate of a triple receptor negative breast cancer cell line.

Methods: Three cell lines, 185B5 normal tissue, HCC38, and AU585, were seeded with peptide p1978. Corresponding plates were seeded with PBS to serve as controls. Baseline line cell counts were taken at $30 \%$ confluence prior to seeding. Counts were again made 48 hours later.

Results: The HCC38 cell line showed decreased growth when exposed to the low and high dose of p1978 peptide. Conclusion: The results suggest that p1978 may have potential in treating triple receptor negative breast cancer.
\end{abstract}

Key Words: Saliva, Breast cancer, Proline rich peptides, Triple negative breast cancer, Cancer signaling

\section{INTRODUCTION}

Carcinoma of the breast is the second most common type of cancer among women primarily affecting the ductal and lobular tissues of the breast. The affliction constitutes a major public health burden. ${ }^{[1,2]}$ Despite improved early detection, diagnosis and aggressive treatment approaches, consisting of surgery, radiotherapy and/or chemotherapy, carcinoma of the breast is still a great threat to human life. ${ }^{[1,2]}$ Regardless of these advances, we still have an incomplete knowledge of the molecular principles underlying the malignant progression as well as the development and maintenance of local recurrence and distant metastasis of this cancer type. ${ }^{[1,2]}$ Additionally, there is also the problem in rendering treatment of triple negative breast carcinomas, which are more aggressive than other types of breast cancer and respond poorly to treatments such as hormonal and Her2/neu receptor therapy.

Current research suggests that carcinoma of the breast may alter the protein profile of secretions produced by other exocrine tissues such as the lacrimal and salivary glands. ${ }^{[3,4]}$ One salivary protein that has been repeatedly found upregulated among salivary proteomic analysis is the submaxillary gland androgen-regulated protein 3B (SMR3B; P02814).

The SMR3B is an 8.188 kilodalton protein that belongs to the gene family whose other members are SMR3A and PROL1, which all produce opiorphin homologs. ${ }^{[5]}$ Opiorphins are small peptides derived by post-translational processing from their parent proteins. Opiorphins have been identified as a novel class of peptides that act as potent endogenous membrane metalloendopeptidase inhibitors. ${ }^{[5]}$ To date, there is a paucity of knowledge on the expression and function of opiorphin coding genes both in health and in particular, the pathogenesis and malignant progression of breast cancer. Consequently, the purpose of this study was to determine the effects, if any, on the growth triple negative breast cancer

\footnotetext{
*Correspondence: Charles F. Streckfus; Email: charles.streckfus@uth.tmc.edu; Address: Department of Diagnostic and Behavioral Sciences, University of Texas School of Dentistry, Behavioral \& Biomedical Sciences Building, 1941 East Road, Rm. 5322, Houston, Texas 77054, United States.
} 
cell line by inoculating it with a proline rich peptide segment (p1978) from the parent SMR3B protein.

\section{Methods}

\subsection{Experimental design}

The experimental design (see Figure 1) was to seed the HCC 38 breast cancer cell line (BCCL) with the p1978 peptide in order to determine the effects of the peptide on cell growth. The HCC 38 cell line was chosen because of its triple negative receptor status. Triple negative tumors generally do not respond to receptor-targeted treatments and can be particularly aggressive. They are more likely to recur than

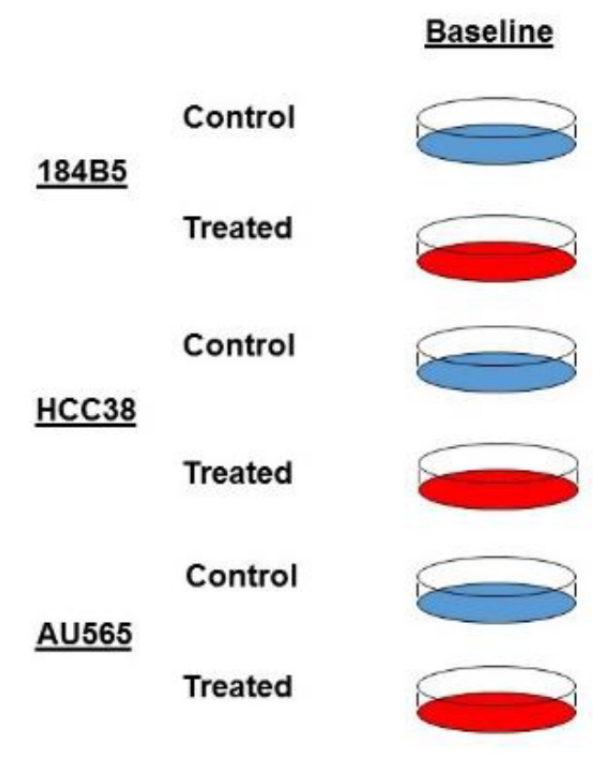

Figure 1. Experimental design schematic

As shown in Figure 1, seeding with p1978 for both experiments was initiated at $30 \%$ confluence in the culture medium at $0.1 \times$ FBS (fetal bovine serum). Corresponding unseeded cell lines served as controls. The controls were treated with a placebo containing $1.0 \mathrm{ml}$ of sterile PBS (for cell culture). An expanded dose-response experiment was not performed due to limited resources. The experiment ended 48 hours after seeding. The outcome variables of this study were total cell count, live cell count and percent viability.

\subsection{Peptide synthesis}

In a previous proteomic studies, LC-MS/MS analysis of saliva the proline rich protein SMR3B (P02814) was found to be up-regulated in saliva secondary to carcinoma of the breast in situ. ${ }^{[7]}$ The proline rich peptide P.RGPYPPGPLAPP.Q (p1978) was the most abundant peptide segment in identifying the total protein SMR3B. other subtypes of breast cancer. ${ }^{[6]}$

The 184B5 (normal breast tissue cells) were seeded to serve as a negative control while the AU565 BCCL, a cell line with a positive Her2/neu and p53 receptor status, was inoculated to serve as a positive control. In the initial phase, treatment cell lines were treated with $8.26 \mu \mathrm{g} / \mathrm{ml}$ of $\mathrm{p} 1978$. The concentration corresponds closely to the average SMR3B (the parent protein of the 1978 peptide), concentration, plus one standard deviation found in healthy breast tissues. A second experiment was performed doubling the concentration of 1978 to $16.52 \mu \mathrm{g} / \mathrm{ml}$. Figure 1 represents a schematic of the design used for the study.

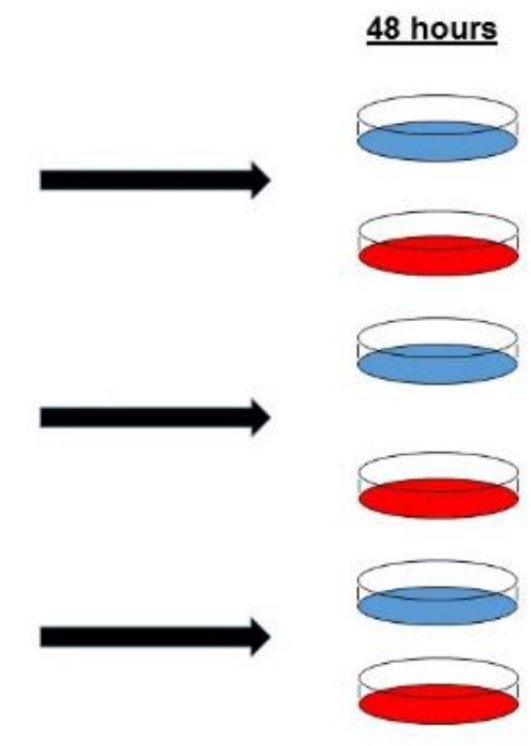

The total coverage of the SMR3B (MKSLTWILGL ${ }^{10}$ WALAACFTPG $^{20}$ ESQRGPRGPY $^{30}$ PPGPLAPPQP $^{40}$ FGPGFVPPPP $^{50}$ PPPYGPGRIP $^{60}$ PPPPAPYGPG ${ }^{70}$ IFPPPPPQP) was $67 \%$ with p1978 being involved with $76 \%$ of the polypeptide coverage.

New England Peptide ${ }^{\mathrm{TM}}$ (Gardner, MA) synthesized peptide p1978 using their proprietary technology. Purity was determined by HPLC and was to be greater than $85 \%$. The peptide was supplied as a lyophilized powder and required reconstitution.

\subsection{Cell lines}

Human breast cell lines HCC38 (HCC38 BL (ATCC ${ }^{\circledR}$

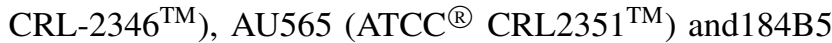
(ATCC ${ }^{\circledR}$ CRL-8799 ${ }^{\mathrm{TM}}$ ) were purchased from the American Type Culture Collection. Cell line descriptions are summarized in Table 1. 
Table 1. Cell types with receptor status

\begin{tabular}{llll}
\hline Cell line & Disease & Cell type & Receptors \\
\hline 184B5 & Normal & Chemically transformed & N/A \\
HCC38 & Adenocarcinoma & Stage IIB tumor & $\mathrm{ER}^{-}, \mathrm{PR}^{-}, \mathrm{Her}^{-}$ \\
AU565 & Adenocarcinoma & Pleural effusion & $\mathrm{Her2}^{+}, \mathrm{Her}^{+}, \mathrm{Her}^{+}, \mathrm{p}^{+} 3^{+}$ \\
\hline
\end{tabular}

\subsection{Cell growth procedures}

The aforementioned cell lines were thawed in a $37^{\circ} \mathrm{C}$ water bath with gentle agitation. The vials were decontaminated and the cells were added drop wise to $9 \mathrm{ml}$ of their prospective culture media while gently mixing. The cell suspension was centrifuged at $1,000 \mathrm{rpm}$ for five minutes. The supernatant was carefully removed and the cell pellet was resuspended in $5.0 \mathrm{ml}$ of media. Each cell line was checked for viability using a hemocytometer and a cell count $/ \mathrm{ml}$ was calculated. Nine plates were seeded of each cell line at a total of $1.0 \times 10^{6}$ cells $/ 100 \mathrm{~mm}$ plates. Once the plates reached $30 \%$ confluency, nine plates of each cell line were treated with $8.26 \mu \mathrm{g} / \mathrm{ml}(4.95 \mu \mathrm{M})$ of $\mathrm{p} 1978$ peptide and a set of nine control plates were treated with $1.0 \mathrm{ml}$ of phosphate buffered saline (PBS). They were incubated and harvested by trypsinization in 48 hours. The cells from each plate were counted for the total number of cells and were assessed for viability using the trypan blue exclusion test of cell vi- ability. The same procedures were repeated for the higher $16.52 \mu \mathrm{g} / \mathrm{ml}(9.88 \mu \mathrm{M})$ dose.

\subsection{Statistics}

Data was tabulated using SPSS statistical software. The outcome variables of this study were total cell count, live cell count and percent viability. To assess these variables, descriptive statistics were employed to compare p1978 treated cells relative to the control cells. The approach consisted mainly of bar charts, mean cell counts and mean percentages. The cellular growth rate was determined by subtracting the resultant or final cell count from its baseline value. The difference was divided by 48 hours the growing time for the cells. The results were expressed in cells/hour.

A homoscedastic univariate $t$-test was computed for differences between the treated and the control groups. The arithmetic mean value of the control group was used as the "cutpoint" value. The alpha level was $p<.05$.

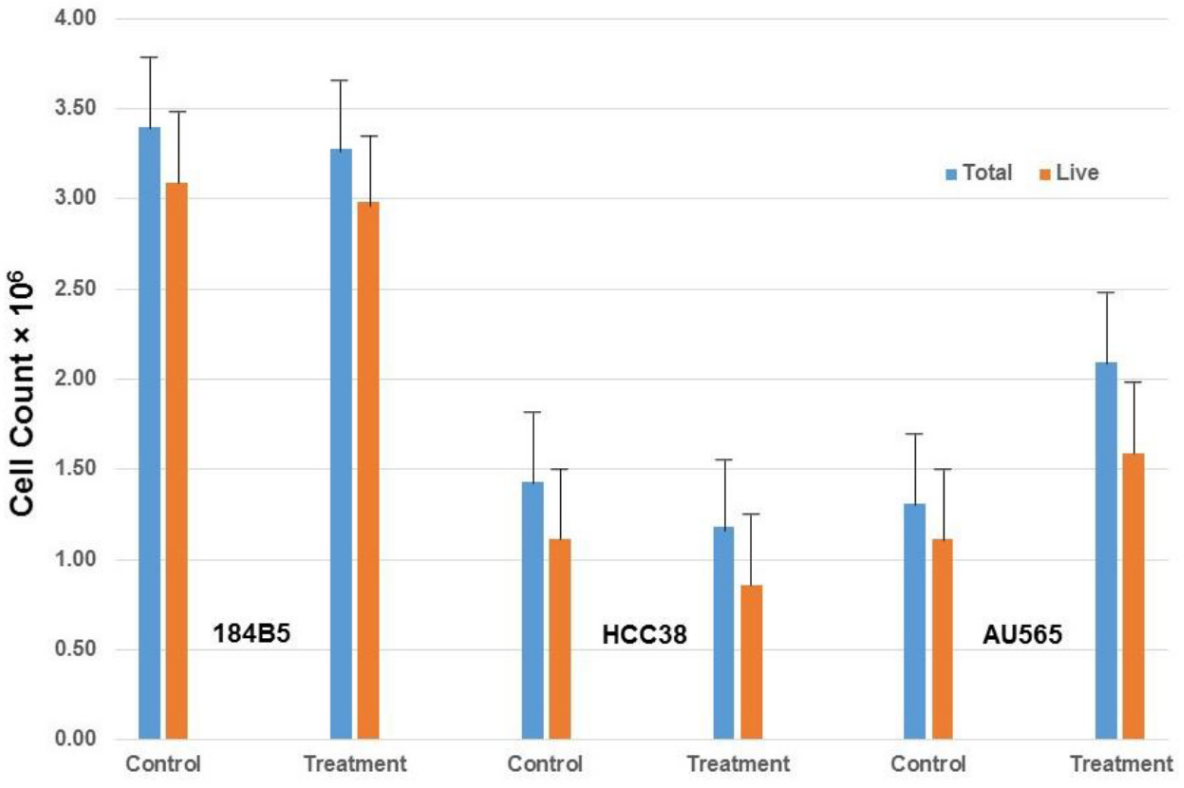

Figure 2. Bar graph exhibiting mean cell line values with standard deviations for $8.26 \mu \mathrm{g} / \mathrm{ml}$ of p1978

\section{RESUlts}

\subsection{Dosing cell lines with $8.26 \mu \mathrm{g} / \mathrm{ml}$ of p1978}

The results of this experiment are illustrated in Table 2 and Figure 2. The 184B5 cell line (normal breast tissue) exhib- ited slightly higher cell counts for the treated cells for both total $(7.5 \%)$ and living cell counts $(3.5 \%)$ as compared to the control. The addition of the peptide produced an almost negligible difference in growth rate between the treated and the controls. 
Table 2. Mean cell line values with standard deviations for $8.26 \mu \mathrm{g} / \mathrm{ml}$ dose of p1978

\begin{tabular}{|c|c|c|c|c|}
\hline Cell line & Status & Total $\times 10^{6}$ & Live $\times 10^{6}$ & \% Live \\
\hline \multirow{6}{*}{ 184B5 } & Baseline & 2.75 & 2.70 & 98 \\
\hline & Control & $3.40( \pm 0.95)$ & $3.09( \pm 0.96)$ & 91 \\
\hline & Treated & $3.66( \pm 1.00)$ & $3.19( \pm 0.91)$ & 82 \\
\hline & Control - Baseline & 0.65 & 0.39 & - \\
\hline & Treated - Baseline & 0.91 & 0.49 & - \\
\hline & Treated - Control & 0.26 & 0.10 & - \\
\hline \multirow{6}{*}{ НСС38 } & Baseline & 1.12 & 1.04 & 93 \\
\hline & Control & $1.41( \pm 0.28)$ & $1.18( \pm 0.26)$ & 84 \\
\hline & Treated & $1.11( \pm 0.27)$ & $0.78( \pm 0.21)$ & 71 \\
\hline & Control - Baseline & 0.29 & 0.14 & - \\
\hline & Treated - Baseline & -0.01 & -0.26 & - \\
\hline & Treated - Control & -0.30 & -0.40 & - \\
\hline \multirow{6}{*}{ AU565 } & Baseline & 1.43 & 1.21 & 85 \\
\hline & Control & $1.21( \pm 0.47)$ & $0.96( \pm 0.39)$ & 80 \\
\hline & Treated & $1.59( \pm 0.89)$ & $1.12( \pm 0.81)$ & 61 \\
\hline & Control - Baseline & -0.22 & -0.25 & - \\
\hline & Treated - Baseline & 0.16 & -0.09 & - \\
\hline & Treated - Control & 0.38 & -0.16 & - \\
\hline
\end{tabular}

Unlike the $184 \mathrm{~B} 5$ cell line, the HCC38 cell line produced a $20.8 \%$ and a $33.2 \%$ reduction for both total and living cell counts respectively. Both cell counts exhibited a similar knock down trend; however, the living cell count was nearly significant from the control at $t=-3.25$ and a $p$ value of .08. While not statistically significant, it may be clinically relevant. Treated HCC38 growth rate is over lower than control HCC38 growth rate. The AU565 cell line percent viability was lower for the treated AU565 as compared to the control (61\% vs. $80 \%)$. The total $(31.5 \%)$ and live $(11.7 \%)$ cell count values in the treated AU565 line were higher than AU565 control group.

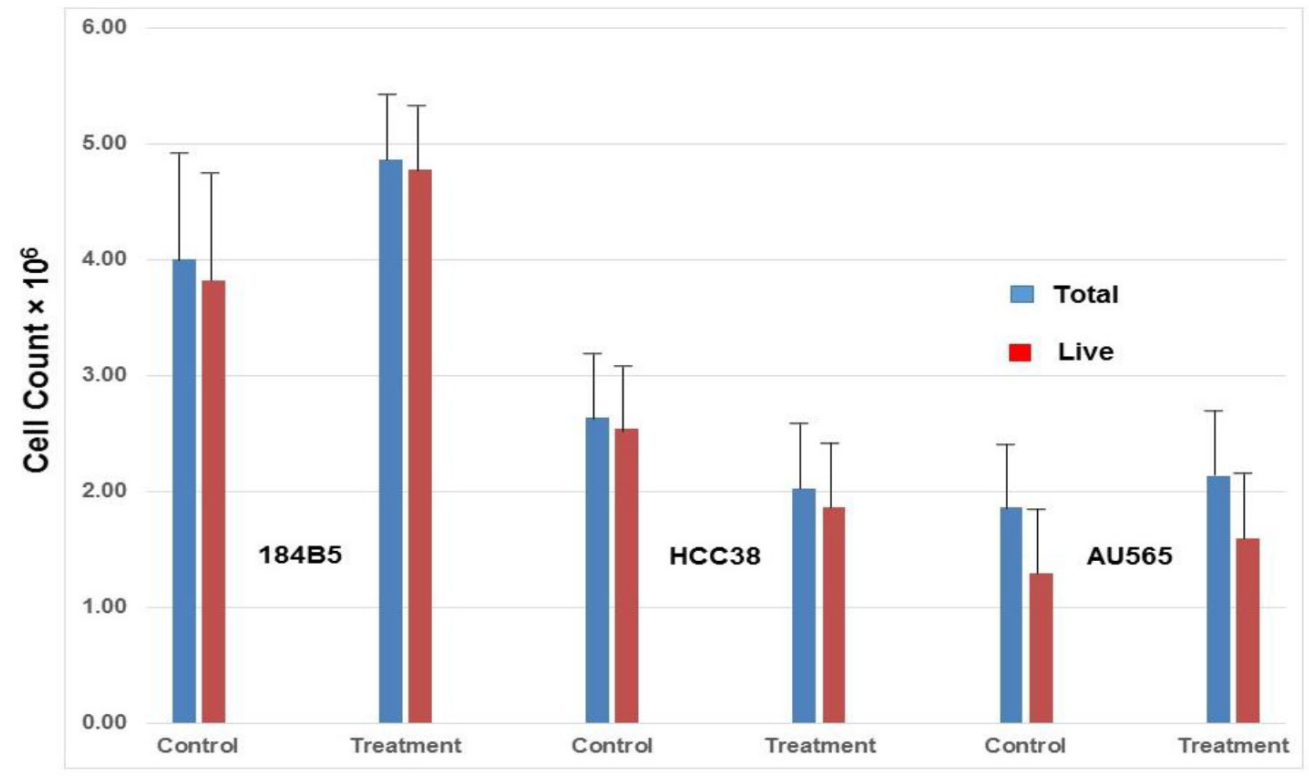

Figure 3. Bar graph exhibiting mean cell line values with standard deviations for $16.52 \mu \mathrm{g} / \mathrm{ml}$ of p1978

\subsection{Dosing cell lines with $16.52 \mu \mathrm{g} / \mathrm{ml}$ of $\mathbf{p} 1978$}

The results of this experiment are illustrated in Table 3 and Figure 3. As illustrated in Table 3 and Figure 3, there was an increase in the total $(22.4 \%)$ and living $(63.7 \%)$ cell counts Published by Sciedu Press for the treated 184B5 cells as compared to the control. There was no effect, however, on cell viability or growth rate (see Table 4). 
Table 3. Mean cell line values with standard deviations for $16.52 \mu \mathrm{g} / \mathrm{ml}$ dose of p1978

\begin{tabular}{lllll}
\hline Cell line & Status & Total $\times \mathbf{~ 1 0}^{\mathbf{6}}$ & Live $\times \mathbf{1 0}^{\mathbf{6}}$ & \% Live \\
\hline \multirow{4}{*}{$184 B 5$} & Baseline & 2.29 & 2.25 & $\mathbf{9 8 \%}$ \\
& Control & $4.01( \pm 1.06)$ & $3.82( \pm 0.99)$ & $\mathbf{9 5 \%}$ \\
& Treated & $4.91( \pm 0.63)$ & $4.82( \pm 0.75)$ & $\mathbf{9 8 \%}$ \\
& Control - Baseline & 1.72 & 1.57 & - \\
& Treated - Baseline & 2.62 & 2.57 & - \\
& Treated - Control & 0.90 & 1.00 & $\mathbf{7 7 \%}$ \\
& Baseline & 1.00 & 0.77 & $\mathbf{9 6 \%}$ \\
& Control & $2.64( \pm 0.75)$ & $2.54( \pm 0.69)$ & $\mathbf{9 2 \%}$ \\
& Treated & $2.03( \pm 0.62)$ & $1.87( \pm 0.43)$ & - \\
& Control - Baseline & 1.64 & 1.77 & - \\
& Treated - Baseline & 1.03 & 1.10 & $\mathbf{7 2 \%}$ \\
& Treated - Control & -0.61 & -0.67 & $\mathbf{7 0 \%}$ \\
& Baseline & 1.90 & 1.36 & $\mathbf{7 5 \%}$ \\
& Control & $1.87( \pm 0.56)$ & $1.30( \pm 0.44)$ & - \\
\end{tabular}

Note. $*$ represents $10^{5}$.

With respect to the HCC38 cell line, the average total number of cells were higher in then control $(22.4 \%)$ than in treated HCC38 cell line indicating a knockdown effect on HCC38 cell line. Likewise, there was a $37.9 \%$ decrease in the number of living cells in the seeded HCC 38 cell line as compared to the control. This was statistically significant $(t=-3.08 ; p$ $<.05)$. As shown in Table 4, the HCC38 treated group had a lower growth rate than control (-38\% difference).
The average total cells were lower in control than in treated AU565 cell line. No knockdown effect was observed among the AU565 cell lines as observed in the in the HCC38 cell line. Additionally, there was an effect on the percent viability as it indicated a $23.1 \%$ increase in living cell count. The AU565 treated group also exhibited a growth rate higher than the control (see Table 4).

Table 4. Growth rates for cell lines expressed as cells/hour

\begin{tabular}{|c|c|c|c|c|}
\hline & Cell line & Status & Total growth rate & Live growth rate \\
\hline \multirow{6}{*}{$\begin{array}{l}\text { Dosing cell lines with } \\
8.26 \mu \mathrm{g} / \mathrm{ml} \text { of p1978 }\end{array}$} & \multirow{2}{*}{ 184B5 } & Control & 1.36 & 0.81 \\
\hline & & Treated & 1.11 & 0.59 \\
\hline & \multirow{2}{*}{ НСС38 } & Control & 0.60 & 0.29 \\
\hline & & Treated & N.G. & N.G. \\
\hline & \multirow{2}{*}{ AU565 } & Control & N.G. & N.G. \\
\hline & & Treated & 1.38 & 0.77 \\
\hline \multirow{6}{*}{$\begin{array}{l}\text { Dosing cell lines with } \\
16.52 \mu \mathrm{g} / \mathrm{ml} \text { of } \mathrm{p} 1978\end{array}$} & \multirow{2}{*}{ 184B5 } & Control & 4.56 & 3.28 \\
\hline & & Treated & 7.83 & 2.77 \\
\hline & \multirow{2}{*}{ НСС38 } & Control & 3.42 & 3.69 \\
\hline & & Treated & 2.16 & 2.29 \\
\hline & \multirow{2}{*}{ AU565 } & Control & N.G. & N.G. \\
\hline & & Treated & 0.50 & 0.50 \\
\hline
\end{tabular}

Note. ${ }^{*}$ represents $10^{4}$; N.G. = Negative Growth.

\section{Discussion}

As stated in the results the p1978 peptide, in both high and low doses, appears to inhibit cell growth. With respect to 42 the HCC38 cell lines, the overall effect appeared to remain the same with a few exceptions. When the concentration of p1978 increased, it yielded a corresponding increase in 
cell viability. Additionally, there was a decrease in the difference between the control and treatment groups cell counts. Growth rate decreased regardless of dosage; however, the lower dosage appeared to have a higher impact on the rate of cell growth. With respect to the 184B5 and AU565 cell lines, the low dose had minor effect on the 184B5 and AU565 cell lines; however, this was not the case when the dose was doubled.

Starting with the 184B5 cell line, doubling the concentration of p1978 produced several interesting findings. As exhibited in Table 2 and Table 3, the mean number of cells increased among the 184B5 cell lines. The treated cell lines became higher in cell counts than the control. This was in contrast to lower dose results where the treatment group produced cell counts below that of the control. The higher dose also appeared to increase cell viability from 91 to between 95 to 98 percent. The growth rates also increased with a higher p1978 concentration (see Table 4). The AU565 cell line exhibited a positive response to both dosages. The cell counts for the treated cells where higher than controls and the treated cells exhibited a higher growth rate when compared to its counterpart.

As mentioned in the introduction, there is a dearth of information in the literature regarding salivary proline rich peptides and its relationship to breast cancer progression. With this in mind, the authors will attempt to explain the aforementioned findings regarding HCC38 cell growth inhibition from a molecular basis.

One of the hallmarks of salivary proline rich peptides is their ability to cross cell membranes without damage and exploit intracellular activity. ${ }^{[8]}$ This, indeed, may be the case with p1978. Once inside the cell, p1978 may interact with the $\mathrm{SH} 3$ as illustrated in Figure 4, which diagrams its possible effects on the Ras pathway. As shown in Figure 4, the pathway begins with a ligand activated growth factor receptor that produces a tyrosine kinase receptor response. Consequently, Grb2, an adaptor protein, interacts via its $\mathrm{SH} 2$ domain with the autophosphorylated carboxyl-terminal tail of the activated receptor and via the SH3 domains with proline-rich sequences found in the Ras guanine releasing factor (Sos). The cascade of events lead to Ras activation. ${ }^{[9-13]}$

As previously mentioned, Grb2 has two $\mathrm{SH} 3$ domains that recognize the PxxP consensus sequence. ${ }^{[11]}$ The PxxP sequence is also present in the p1978 peptide. ${ }^{[9-13]}$ With this in mind, it may be possible that p1978 peptide has a higher affinity to the Grb2/SH3 domains thereby inhibiting Ras activation by blocking Sos binding to Grb2 in the HCC38 cell line (see Figure 4). This in turn may reduce cellular proliferation. Further research is required in order to validate these events.
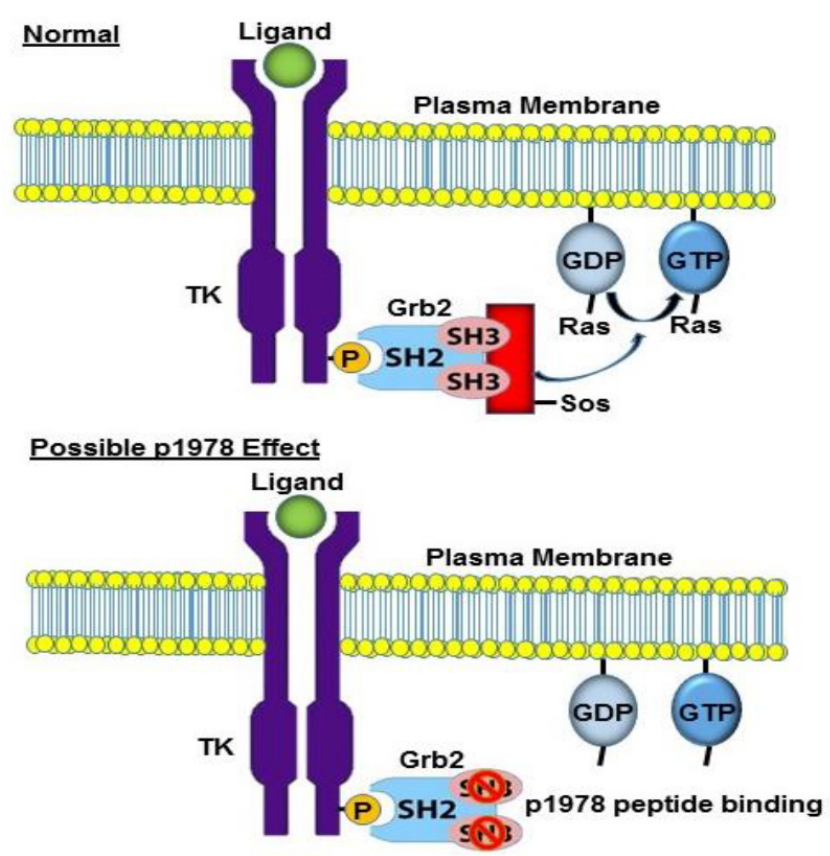

Figure 4. Possible inhibition of Ras pathway by p1978

The literature suggests several alternative mechanisms. For example, there is the possibility that p1978 is acting similar to p1932 in which Palmerini et al. have shown inhibits the proliferation of squamous cell carcinoma by having an antagonistic effect on the cytosolic $\mathrm{Ca}^{2+}$ response induced by progesterone. ${ }^{[14]}$ Their findings suggest that p1932 interferes with the molecular interplay between PGRMC1, a progesterone receptor and $\mathrm{mPR} \alpha$ by acting as an inhibitor of the binding associated with the proline rich sequences of PGRMC1 to SH3 domains of certain kinases. ${ }^{[14,15]}$

Similarly, Hashimoto et al. used a cell permeable peptide derived from the AMAP1 peptide that blocks cortactin binding in breast cancer cell lines. This peptide, like the aforementioned peptides, also blocks or interferes with the SH3/proline interactions. ${ }^{[16]}$

From a molecular perspective, Zhang et al. also suggest that proline rich acidic proteins can be epigenetically regulated and inhibit malignant cell growth. In this study, the authors were able to induce genetic over expression of the human homologue PRAP gene, which reduced cell numbers in HepG2 and Hela cells. Among cancer cells, the PRAP gene is normally down regulated by methylation and deacetylation. ${ }^{[17]}$

In conclusion, the data suggests that there appears to be a reduction of triple receptor negative cell growth associated with proline rich peptides; in this case peptide p1978. More 
research is required to make the preliminary findings more robust. A dose curve needs to be constructed in order to determine the maxim effect of p1978 on cell growth. Additionally, other breast cancer cell lines needed to be tested using the growth inhibiting p1978 peptide. Other carcinomas from differing sites should also be assessed.

\section{CONFlicts OF InTEREST Disclosure}

The authors declare that there is no conflict of interest statement.

\section{REFERENCES}

[1] Kiberstis P, Roberts L. A race still unfinished. Science. 2014 343: 1451. PMid:24675947. https://doi.org/10.1126/scie nce.343.6178.1451

[2] Servick K. Breast cancer: A world of difference. Science. 2014; 343 : 1452-3. PMid:24675948. https : //doi .org/10.1126/science 343.6178 .1452

[3] Lebrecht A, Boehm D, Schmidt M, et al. Diagnosis of breast cancer by tear proteomic pattern. Cancer Genomics Proteomics. 2009; 6: 177-82. PMid:19487546.

[4] Eccles SA, Aboagye EO, Ali S, et al. Clinical research gaps and translational priorities for the successful prevention and treatment of breast cancer. Breast Cancer Res. 2013; R92. PMid:24286369. https://doi.org/10.1186/bcr3493

[5] Koffler J, Holzinger D, Sanhueza GA, et al. Submaxillary gland androgen-regulated protein $3 \mathrm{~A}$ expression is an unfavorable risk factor for the survival of oropharyngeal squamous cell carcinoma patients after surgery. Eur Arch Otorhinolaryngol. 2013; 270(4): 1493-500. PMid:23053383. https ://doi.org/10.1007/s00405 $-012-2201-6$

[6] Neve RM, Chin K, Fridlyand J, et al. A collection of breast cancer cell lines for the study of functionally distinct cancer subtypes. Cancer Cell. 2006; 10(6): 515-27. PMid:17157791. https: //doi.org/10.1016/j.ccr.2006.10.008

[7] Streckfus C, Bigler L. A catalogue of altered salivary proteins secondary to invasive ductal carcinoma: a novel in vivo paradigm to assess breast cancer progression. Scientific Reports. 2016; 30800(6): 1-18. https://doi.org/10.1038/srep30800

[8] Radicioni G, Stringaro A, Molinari A, et al. Characterization of the cell penetrating properties of a human salivary proline-rich peptide. Biochimica et Biophysica Acta. 2015; 1848: 2868-77. PMid:26325345. https ://doi.org/10.1016/j.bbamem. 2015. 08.019
[9] Schlessinger J. SH2/SH3 signaling proteins. Curr Opin Genet Dev. 1994; 4(1): 25-30. https://doi.org/10.1016/0959-437X (94 ) $90087-6$

[10] Kay BK, Williamson MP, Sudol M. The importance of being proline: the interaction of proline-rich motifs in signaling proteins with their cognate domains. FASEB J. 2000; 14: 231-41. PMid:10657980.

[11] Lemmon MA, Ladbury JE, Mandiyan V, et al. Independent binding of peptide ligands to the $\mathrm{SH} 2$ and $\mathrm{SH} 3$ domains of Grb2. J Biol Chem. 1994; 269(50): 31653-8. PMid:7527391.

[12] Mayer BJ, Baltimore D. Signaling through SH2 and SH3 domains. Trends Cell Biol 1993; 3: 8-13. https://doi.org/10.1016/09 62-8924 (93) 90194-6

[13] Delbruck M. Chapter 6: Cytoplasmic signaling circuitry programs many of the traits of cancer. In: The Biology of Cancer. Weinberg R (edit), New York \& London: Garland Sciences, Taylor \& Francis Group, LLC. 2014: 184-90.

[14] Palmerini CA, Mazzoni M, Radicioni G, et al. Antagonistic Effect of a Salivary Proline-Rich Peptide on the Cytosolic $\mathrm{Ca}^{2+}$ Mobilization Induced by Progesterone in Oral Squamous Cancer Cells. PLoS One. 2016; 11(1): e0147925. PMid:26814504 https://doi.org/10.1371/journal.pone.0147925

[15] Boonyaratanakornkit V, Scott MP, Ribon V, et al. Progesterone receptor contains a proline-rich motif that directly interacts with $\mathrm{SH} 3$ domains and activates c-Src family tyrosine kinases. Mol Cell. 2001; 8(2): 269-80. https://doi.org/10.1016/S1097-2765(01)0 0304-5

[16] Hashimoto S, Hirose M, Hashimoto A, et al. Targeting AMAP1 and cortactin binding bearing an atypical src homology 3/proline interface for prevention of breast cancer invasion and metastasis. Proc Natl Acad Sci USA. 2006; 103(18): 7036-41. PMid:16636290. https://doi.org/10.1073/pnas.0509166103

[17] Zhang J, Wong H, Ramanan S, et al. The proline-rich acidic protein is epigenetically regulated and inhibits growth of cancer cell lines. Cancer Res. 2003; 63(20): 6658-65. PMid:14583459. 